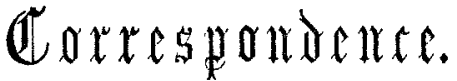

"Audi alteram partem."

\section{THE PRESENT POSITION OF MIDWIVES.}

\section{To the Editor of THE LANCET.}

STR,-As one who is keenly interested in the midwifery outlook may I venture to question whether the optimistic tone in the leading article under the above heading in your issue of Feb. 26th can be altogether justified by fact? We dare not comfort ourselves with the number of midwives upon the roll, as a large proportion have never had the slightest intention to practise, and the mothers and infants of the country would therefore have been equally benefited had they passed an examination in Sanskrit. Your article assures us that there is no shortage of midwives in towns. Neither was there before the Midwives Act was passed, and for the same reason-i.e., the large number of untrained women in practice. In 1914 the Central Midwives Board estimated the numbers of trained and untrained practising midwives as equal. And our training-how far has this been brought after all these years? Is there one midwife in 100-or shall I say 1000 ? - who systematically tries to ascertain and to prevent the complications that threaten her patient at the time of booking? A few may possibly test the urine of primiparæ a month or two before labour, but how many contracted pelves are sent up for advice to our hospitals and consultants on a midwife's finding, or how many women with the habit of abortion for diagnosis and treatment? What ideas has the ordinary midwife on the management of breast feeding (quite an intricate science in itself) and the still more involved details of supplementary or artificial feeding? Her views are mostly bounded by some one tinned food, or else the archaic milk and barley-water, dealt out in unvarying strength and quantity to all comers. It will take us many generations to greatly improve the statistics of our infant mortality if we rest satisfied with our midwives and their training as we find them at present.

Your article admits that there may be some shortage in the country districts, although even then our anxiety is lulled to rest by the statement that "as the old midwives die off they are being replaced by trained women." And yet the 1915 Report of the Local Government Board speaks of 51 villages in Bedfordshire and large areas in Cornwall without a midwife of any kind; "a serious shortage" in parts of Cheshire and Wales; "places very hard to fill" in Wiltshire, and adds significantly, "In the majority of areas with scattered populations the services of a midwife are lacking." In such areas the doctor may be several miles off, and the demand upon the time of the panel doctor may render it impossible to obtain his services at the critical moment. Wales is, of course, one of the blackest spots in the United Kingdom in all matters relating to childbearing; the proportion of bona fide midwives there has always been enormous, and we were not surprised to find in the same report that the total maternal death-rate per 1000 births in that country was quite recently $5^{\circ} 58$, as against $3^{\circ} 86$ for the rest of England, and 3.03 in the poor district of Battersea. In the same way the infant deathrate varies, in the same period of years, between 41 and 18 in 1000, the difference between the two figures showing approximately the number of infant lives that might be saved, even with our present imperfect knowledge, during the first week of life. Other factors undoubtedly influence these statistics, but the skill and wisdom of the attendant at birth and during the puerperium cannot be held a negligible factor. It is no gentle anodyne of a soothing nature that we require in these times of stress and wholesale slaughter, but a drastic rerolution in the training of our young people, and more especially of those who have so great an influence on the life and death of the next generation.

We greet with satisfaction the increased length of training demanded by the Central Midwives Board, but we can hardly consider that the ideal has been attained when we reflect that in order to nurse any sort of disease, to attend any kind of surgical disaster under a doctor a three years' course is necessary. Midwifery has, perhaps, more possibilities of sudden and fatal emergencies than any other branch of the healing art. and it is hardly likely that a woman should be equipped either to diagnose such emergencies beforehand or to deal with them until the arrival of the doctor in one. sixth of the time that it takes her more protected sister to learn how to nurse a case of acute rheumatism or a fractured tibia.

I am, Sir, yours faithfully,

ALICE S. GREGORY,

Honorary Secretary, British Hospital for MFothers and Babies, and National Training School for District Midwives.

Woolwich, March 2nd, 1916.

\section{WHAT IS THE SIMPSON LIGHT?}

\section{To the Editor of THE LANCET.}

SIR,--In your issue of March 4th an article appears by Dr. J. A. Menzies on the Treatment of Septic Wounds with the Simpson. Light. The following good effects are claimed: (1) relief of pain; (2) increase of movement; (3) relief of swelling; (4) absorption of scar tissue; (5) stimula. tion of unhealthy granulation tissue; and (6) diminu. tion of discharge. The author further claims to have had good results in two cases of Graves's disease.

So far as wounds are concerned, there is not one of these good effects which cannot be brought about by judicious $X$ ray treatment; unless, of course, there is some definite surgical cause which prevents their healing. X rays are extensively used at the Cambridge Hospital, Aldershot, for all the above purposes, and especially for the relief of pain and the softening and absorption of scar tissue.

What is the Simpson light? An illuminating discussion at the Electro-therapentical Section of the Royal Society of Medicine in January last brought out the following facts. The spectrum of the Simpson arc appears to be identical with that of tungsten. It is a source of very abundant ultra-violet rays, some of which are rather more penetrating than those from a Finsen lamp. Even the haxdest of them are, however, completely absorbed by 2-3 $\mathrm{mm}$. of human tissue (Sidney Russ). Dr. J. H. Sequeira also showed that the production of erythema of the skin can be prevented by the interposition of thin layers of paper. He concluded that deep effects, when they occur, must be due to counter-irritation.

The Simpson light has been boomed in the public press as a "new kind of X ray." It cannot be too emphatically stated that the radiation from a Simpson arc is in no way related to that from an $X$ ray tube, except in so far as both are forms of 